\title{
ANALISA EFISIENSI TRANSFORMATOR PENYULANG YANG DIPENGARUHI OLEH KETIDAKSEIMBANGAN BEBAN MENGGUNAKAN APLIKASI ETAP 12.6.0
}

\author{
Mutiar $^{1}$ / Grito Sampurno ${ }^{2}$ \\ mutiar.tiar@gmail.com \\ Dosen Teknik Elektro Prodi Teknik Listrik Politeknik Negeri Sriwijaya Palembang ${ }^{1}$ \\ Mahasiswa Teknik Elektro Prodi Teknik Listrik Politeknik Negeri Sriwijaya Palembang ${ }^{2}$
}

\begin{abstract}
ABSTRAK
Beban yang tidak merata ini akan menyebabkan ketidakseimbangan pada jaringan, sehingga akan menimbulkan arus yang mengalir pada penghantar netral yang menyebabkan rugi-rugi daya dan penurunan efisiensi pada transformator. Penelitian ini dilakukan untuk menganalisa efisiensi transformator penyulang yang dipengaruhi oleh ketidakseimbangan beban dengan simulai ETAP 12.6.0. Setelah dilakukan perhitungan dan dianalisis didapatkan efisiensi transformator tertinggi terjadi pada trafo gardu PA 0513 sebesar sebesar 97,59\% untuk data lapangan sedangkan pada simulasi ETAP pada gardu PA 0637 sebesar 97,4\%, dan efisiensi trafo gardu terendah terjadi pada PA 0566 sebesar 48,6\% untuk data lapangan dan 49,05\% untuk simulasi ETAP.
\end{abstract}

Kata Kunci $\quad$ : Ketidakseimbangan Beban, Rugi Daya, Efisiensi, Transformator.

\section{PENDAHULUAN}

\subsection{Latar Belakang}

Ketidakseimbangan beban dipengaruhi oleh pemakaian pada beban satu fasa R, S, dan T yang beroperasi tidak merata. Pembagian awal beban listrik tiap fasa pada jaringan tegangan rendah sebenarnya sudah merata namun, seiring dengan bertambahnya jumlah pelanggan yang ingin menggunakan jasa energi listrik khususnya pemasangan sambung baru beban yang dilakukan tidak merata, sehingga menimbulkan rugi-rugi daya listrik dan sistem pendistribusian ke pelanggan tidak stabil. Oleh karena itu, dalam penelitian ini penulis tertarik mengangkat judul mengenai "Analisisa Efisiensi Transformator Penyulang Yang Dipengaruhi Oleh Ketidakseimbangan Beban Menggunakan Aplikasi ETAP 12.6.0 ”.

\subsection{Tujuan Penelitian}

Adapun tujuan dari penelitian ini adalah sebagai berikut :

1. Untuk mengetahui keadaan beban puncak gardu distribusi pada penyulang Harimau.

2. Untuk mengetahui pengaruh yang diakibatkan dari keadaan ketidakseimbangan beban gardu distribusi pada penyulang Harimau.

\subsection{Manfaat Penelitian:}

Adapun manfaat dari penelitian ini adalah sebagai berikut :

1. Dapat menjelaskan keadaan beban puncak gardu distribusi pada penyulang Harimau.

2. Dapat menjelaskan pengaruh yang diakibatkan dari keadaan ketidakseimbangan beban gardu distribusi pada penyulang Harimau.

\subsection{Ruang Lingkup Penelitian}

Pada penelitian ini penulis telah membatasi ruang lingkup pembahasan agar isi dan pembahasan menjadi terarah dan dapat dicapai hasil yang diharapkan. Adapun batasan masalah yaitu menganalisa hasil perhitungan dari pengaruh ketidakseimbangan beban terhadap efisiensi transformator dan meggunakan perbandingan Aplikasi ETAP12.6.0.

Analisa Efisiensi Transformator Penyulang Yang Dipengaruhi Oleh Ketidakseimbangan Beban Menggunakan Aplikasi Etap 12.6.0

(Mutiar / Grito Sampurno) 


\section{TINJAUAN PUSTAKA}

\subsection{Rugi - Rugi Transformator ${ }^{4}$

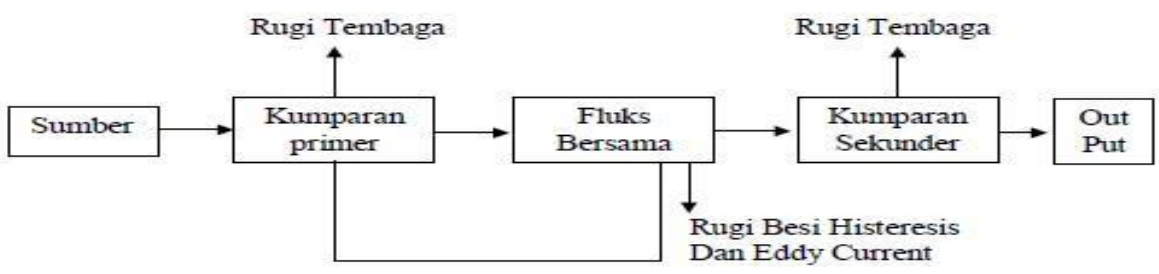

Gambar 2.1 Blok Diagram Rugi-Rugi Pada Transformator.

\subsection{Efisiensi Transformator}

Efisiensi menunjukan tingkat keefisienan kerja suatu peralatan, dalam hal ini transformator yang merupakan perbandingan rating output (keluaran) terhadap input-nya (masukkan) yang dinyatakan dengan persamaan berikut:

$$
\begin{aligned}
\text { Efisiensi }(\eta) & =\frac{\text { Pout }}{\text { Pin }} \\
= & \frac{\text { Pout }}{\text { Pout }+ \text { rugi-rugi }} \times 100 \%
\end{aligned}
$$

Maka persentase efisiensi adalah :

$$
=\frac{\text { Pout }}{\text { Pout }+\sum \text { rugi-rugi }} \times 100 \%
$$

dimana:

$$
\begin{array}{ll}
\text { Pin } & =\text { Daya input transformator } \\
\text { Pout } & =\text { Daya output transformator } \\
\text { Srugi }- \text { rugi } & =\mathrm{Pcu}+\mathrm{Pi}
\end{array}
$$

\subsection{Perhitungan Arus Beban Penuh Transformator}

Daya transformator bila ditinjau dari sisi tegangan tinggi (primer) dapat dirumuskan sebagai berikut:

$$
\mathrm{S}=\sqrt{3} . \mathrm{V} . \mathrm{I}
$$

dimana :

$$
\begin{array}{ll}
\mathrm{S} & =\text { Daya Transformator }(\mathrm{kVA}) \\
\mathrm{V} & =\text { Tegangan sisi primer transformator }(\mathrm{kV}) \\
\mathrm{I} & =\text { Arus jala }- \text { jala }(\mathrm{A})
\end{array}
$$

Sehingga untuk menghitung arus beban penuh (full load) dapat menggunakan rumus : $\mathrm{I}_{\mathrm{FL}}=\frac{S}{\sqrt{3} V}$

dimana :

$$
\begin{array}{ll}
\mathrm{I}_{\mathrm{FL}} & =\text { Arus beban penuh }(\mathrm{A}) \\
\mathrm{S} & =\text { Daya Transformator }(\mathrm{kVA}) \\
\mathrm{V} & =\text { Tegangan sisi sekunder transformator }(\mathrm{kV})
\end{array}
$$

Besarnya persentase kenaikan beban yang dilayani dapat dihitung dengan :

$\%$ pembebeanan $=\frac{\text { Irata }- \text { rata beban }}{\text { Ibeban penuh transformator }} \times 100 \%$

dimana :

$\mathrm{I}_{\text {rata }- \text { rata beban }}=$ Arus rata - rata beban yang digunakan $(\mathrm{A})$

$\mathrm{I}_{\text {beban penuh transformator }}=$ Arus beban penuh transformator $(\mathrm{A})$

Analisa Efisiensi Transformator Penyulang Yang Dipengaruhi Oleh Ketidakseimbangan Beban Menggunakan Aplikasi Etap 12.6.0 


\subsection{Ketidakseimbangan Beban ${ }^{2}$}

Yang dimaksud dengan keadaan seimbang adalah suatu keadaan dimana:

1. Ketiga vector arus / tegangan sama besar.

2. Ketiga vektor saling membentuk sudut 120 .

Sedangkan yang dimaksud dengan keadaan tidak seimbang adalah keadaan dimana salah satu atau kedua syarat keadaan seimbang tidak terpenuhi. Kemungkinan keadaan tidak seimbang ada tiga, yaitu:

1. Ketiga vektor sama besar tetapi tidak membentuk sudut $120^{\circ}$ satu sama lain.

2. Ketiga vektor tidak sama besar tetapi membentuk sudut $120^{\circ}$ satu sama lain.

3. Ketiga vektor tidak sama besar dan tidak membentuk sudut $120^{\circ}$ satu sama lain.

Pada gambar 2.26a menunjukkan diagram vektor arus dalam keadaan seimbang. Disini terlihat bahwa penjumlahan ketiga vektor aruisnya (IR, IS, IT) adalah sama dengan nol sehingga tidak muncul arus netral (IN). Sedangkan pada gambar 2.26b menunjukkan vektor diagram arus yang tidak seimbang. Disini terlihat bahwa penjumlahan ketiga vektor arusnya $\left(I_{R}, I_{S}, I_{T}\right)$ tidak sama dengan nol sehingga muncul sebuah besaran yaitu arus netral (IN) yang besarnya bergantung dari seberapa besar faktor ketidakseimbangannya.
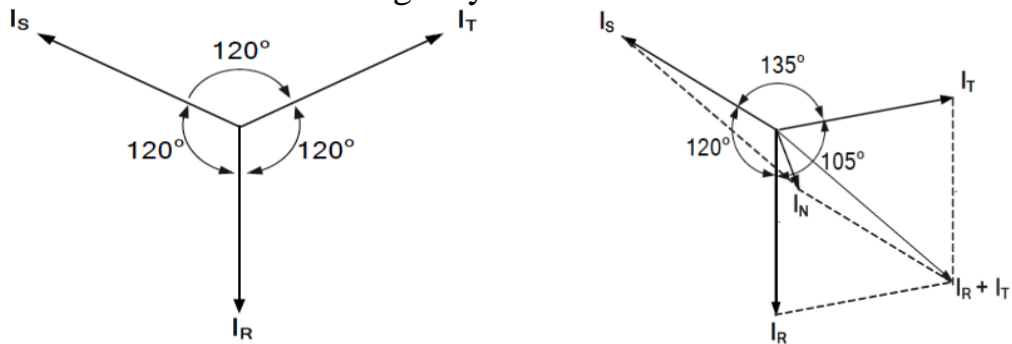

Gambar 2.2 Vektor Diagram Arus.

\subsection{Perhitungan Ketidakseimbangan Beban ${ }^{3}$}

$\mathrm{I}_{\text {rata }- \text { rata }} \quad=\frac{I R+I S+I T}{3}$

Dimana besarnya arus fasa dalam keadaan seimbang (I) sama dengan besarnya arus rata rata, maka koefisien $\mathrm{a}, \mathrm{b}$ dan $\mathrm{c}$ diperoleh dengan :

$$
\begin{aligned}
& \mathrm{a}=\frac{I R}{I} . \\
& \mathrm{b}=\frac{I S}{I} . \\
& \mathrm{c}=\frac{I T}{I} .
\end{aligned}
$$

Pada keadaan seimbang, besarnya koefisien a, b, dan c adalah 1 . Dengan demikian rata - rata ketidakseimbangan beban (dalam \%) adalah :

$$
\% \text { ketidakseimbangan }=\frac{\{|a-1|+|b-1|+|c-1|\}}{3} \times 100 \%
$$

\subsection{Rugi-rugi Akibat Adanya Arus Netral Pada Saluran Netral Sekunder Transformator}

Sebagai akibat dari ketidakseimbangan beban antara tiap-tiap fasa pada sisi sekunder trafo (fasa $\mathrm{R}$, fasa $\mathrm{S}$, fasa $\mathrm{T}$ ) mengalirlah arus netral trafo. Arus yang mengalir pada penghatar netral trafo menyebabkan rugi-rugi. Rugi-rugi pada penghantar netral trafo ini dapat dirumuskan sebagai berikut:

$$
\mathrm{PN}=\mathrm{IN} 2 \cdot \mathrm{RN}
$$

Dimana:

$\mathrm{P}_{\mathrm{N}}=$ Rugi-rugi pada penghantar netral trafo (watt) 
$\mathrm{I}_{\mathrm{N}}=$ Arus yang menngalir pada netral trafo (A)

$\mathrm{R}_{\mathrm{N}}=$ Tahanan penghantar netral trafo $(\Omega)$.

\section{METODOLOGI PENELITIAN}

Metode penelitian ini dilakukan dengan pengumpulan data - data trasformator, tranformator yang digunakan adalah transformator penyulang harimau yang mana merupakan salah satu penyulang yang mendapat aliran energy dari trasformator daya 3 (TD-3) dengan kapasitas 30 MVA di gardu induk Siguntang yang lingkup jaringannya di kelola oleh PT. PLN (Persero) WS2JB Unit Layanan Pelanggan (ULP) Rayon Riva.

\subsection{Data Beban Puncak Gardu Distribusi Penyulang Harimau}

Tabel 3.1 Data Beban Puncak Gardu Distribusi Penyulang Harimau 2021

\begin{tabular}{|c|c|c|c|c|c|c|c|c|}
\hline \multirow{2}{*}{ No } & \multirow{2}{*}{$\begin{array}{l}\text { Nama } \\
\text { Gardu }\end{array}$} & \multirow{2}{*}{$\begin{array}{c}\text { Kapasitas } \\
\text { Trafo } \\
\text { (KVA) } \\
\end{array}$} & \multirow{2}{*}{$\begin{array}{c}\text { Waktu } \\
\text { Pengukuran }\end{array}$} & \multirow{2}{*}{ Jurusan } & \multicolumn{4}{|c|}{ Arus (A) } \\
\hline & & & & & $\mathbf{R}$ & $\mathbf{S}$ & $\mathbf{T}$ & $\mathbf{N}$ \\
\hline \multirow{5}{*}{1} & \multirow{5}{*}{ PA0255 } & \multirow{5}{*}{400} & \multirow{5}{*}{$19: 54: 00$} & $\mathrm{~A}$ & 91 & 64 & 81 & 34 \\
\hline & & & & $\mathrm{B}$ & 35 & 64 & 47 & 35 \\
\hline & & & & $\mathrm{C}$ & - & - & - & - \\
\hline & & & & $\mathrm{D}$ & - & - & - & - \\
\hline & & & & Total & 126 & 128 & 128 & 69 \\
\hline \multirow{5}{*}{2} & \multirow{5}{*}{ PA0257 } & \multirow{5}{*}{160} & \multirow{5}{*}{ 20:02:00 } & $\mathrm{A}$ & 48 & 99 & 85 & 39 \\
\hline & & & & $\mathrm{B}$ & 63 & 47 & 37 & 33 \\
\hline & & & & $\mathrm{C}$ & 17 & 0 & 0 & 17 \\
\hline & & & & $\mathrm{D}$ & 5 & 40 & 12 & 33 \\
\hline & & & & Total & 133 & 186 & 134 & 122 \\
\hline \multirow{5}{*}{3} & \multirow{5}{*}{ PA0356 } & \multirow{5}{*}{200} & \multirow{5}{*}{ 19:16:00 } & $\mathrm{A}$ & 106 & 107 & 66 & 48 \\
\hline & & & & $\mathrm{B}$ & 5 & 1 & 0 & 4 \\
\hline & & & & $\mathrm{C}$ & - & - & - & - \\
\hline & & & & $\mathrm{D}$ & - & - & - & - \\
\hline & & & & Total & 111 & 108 & 66 & 52 \\
\hline \multirow{5}{*}{4} & \multirow{5}{*}{ PA0407 } & \multirow{5}{*}{160} & \multirow{5}{*}{$19: 42: 00$} & $\mathrm{~A}$ & 63 & 28 & 40 & 14 \\
\hline & & & & $\mathrm{B}$ & 93 & 81 & 37 & 67 \\
\hline & & & & $\mathrm{C}$ & - & - & - & - \\
\hline & & & & $\mathrm{D}$ & - & - & - & - \\
\hline & & & & Total & 156 & 109 & 77 & 81 \\
\hline \multirow{5}{*}{5} & \multirow{5}{*}{ PA0457 } & \multirow{5}{*}{200} & \multirow{5}{*}{$19: 34: 00$} & $\mathrm{~A}$ & 135 & 147 & 115 & 46 \\
\hline & & & & $\mathrm{B}$ & 0 & 0 & 10 & 10 \\
\hline & & & & $\mathrm{C}$ & 28 & 78 & 43 & 41 \\
\hline & & & & $\mathrm{D}$ & - & - & - & - \\
\hline & & & & Total & 163 & 225 & 168 & 97 \\
\hline \multirow{5}{*}{6} & & & & $\mathrm{~A}$ & 20 & 35 & 54 & 24 \\
\hline & & & & $\mathrm{B}$ & - & - & - & - \\
\hline & PA0513 & 50 & $18: 35: 00$ & $\mathrm{C}$ & - & - & - & - \\
\hline & & & & $\mathrm{D}$ & - & - & - & - \\
\hline & & & & Total & 20 & 35 & 54 & 24 \\
\hline & & & & $\mathrm{A}$ & 0 & 2 & 3 & 4 \\
\hline 7 & PA0566 & 25 & $19: 12: 00$ & $\mathrm{~B}$ & - & - & - & - \\
\hline & & & & $\mathrm{C}$ & - & - & - & - \\
\hline
\end{tabular}

Analisa Efisiensi Transformator Penyulang Yang Dipengaruhi Oleh Ketidakseimbangan Beban Menggunakan Aplikasi Etap 12.6.0 


\begin{tabular}{|c|c|c|c|c|c|c|c|c|}
\hline & & & & D & - & - & - & - \\
\hline & & & & Total & 0 & 2 & 3 & 4 \\
\hline \multirow{5}{*}{8} & \multirow{5}{*}{ PA0637 } & \multirow{5}{*}{100} & \multirow{5}{*}{$19: 25: 00$} & $\mathrm{~A}$ & 28 & 45 & 41 & 16 \\
\hline & & & & $\mathrm{B}$ & - & - & - & - \\
\hline & & & & $\mathrm{C}$ & - & - & - & - \\
\hline & & & & $\mathrm{D}$ & - & - & - & - \\
\hline & & & & Total & 28 & 45 & 41 & 16 \\
\hline \multirow{5}{*}{9} & \multirow{5}{*}{ PA0663 } & \multirow{5}{*}{100} & \multirow{5}{*}{$20: 28: 00$} & $\mathrm{~A}$ & 5 & 22 & 4 & 16 \\
\hline & & & & $\mathrm{B}$ & - & - & - & - \\
\hline & & & & $\mathrm{C}$ & - & - & - & - \\
\hline & & & & $\mathrm{D}$ & - & - & - & - \\
\hline & & & & Total & 5 & 22 & 4 & 16 \\
\hline \multirow{5}{*}{10} & \multirow{5}{*}{ PA0726 } & \multirow{5}{*}{100} & \multirow{5}{*}{ 21:01:00 } & $\mathrm{A}$ & 53 & 27 & 24 & 34 \\
\hline & & & & $\mathrm{B}$ & 52 & 13 & 57 & 41 \\
\hline & & & & $\mathrm{C}$ & - & - & - & - \\
\hline & & & & $\mathrm{D}$ & - & - & - & - \\
\hline & & & & Total & 105 & 40 & 81 & 75 \\
\hline
\end{tabular}

\section{HASIL DAN ANALISA}

\subsection{Hasil Perhitungan Menggunakan Data Lapangan}

\subsubsection{Perhitungan Efisiensi Transformator PA 0257}

Berdasarkan tabel 3.1 terdapat gardu distribusi yang keadaan pembebanannya mengalami ketidakseimbangan dan dapat mempengaruhi efisiensi transformator yang dipakai. Adapun Langkah untuk mencari nilai efisiensi transformator yang dikarenakan pembebanan dalam keadaan tidak seimbang sebagai berikut :

a. Data Transformator

\begin{tabular}{|c|c|c|}
\hline \multirow{2}{*}{\multicolumn{3}{|c|}{ Merk Trafo }} \\
\hline & & \\
\hline Nomor & : PA 0257 & \\
\hline Daya & $: 160 \mathrm{kVA}$ & \\
\hline \multicolumn{3}{|c|}{ Tegangan: 400/230 V } \\
\hline Kabel Input & : AAAC $150 \mathrm{~mm}^{2}, \mathrm{R}$ & $: 0,210 \Omega / \mathrm{km}$ \\
\hline Kabel Output & : NYY $120 \mathrm{~mm}^{2}, \mathrm{R}$ & $: 0,153 \Omega / \mathrm{km}$ \\
\hline $\operatorname{Cos} \varphi$ & $: 0,85$ & \\
\hline Rugi Inti Besi & $: 400 \mathrm{~W}$ & \\
\hline Rugi Tembaga & $: 10.746,873 \mathrm{~W}$ & \\
\hline Rugi Netral & $: 2.277,252 \mathrm{~W}$ & \\
\hline
\end{tabular}

\section{b. Arus Beban Penuh}

Untuk menentukan arus beban penuh maka digunakan rumus pada persamaan (2.21) sebagai berikut:

$$
\begin{aligned}
\mathrm{I}_{\mathrm{FL}} & =\frac{160000}{\sqrt{3} 400} \\
= & 231,2 \mathrm{~A}
\end{aligned}
$$

c. Arus Rata - Rata dan Persentase Beban Puncak

Untuk menghitung besar arus rata- rata maka digunakan rumus pada persamaan (2.23) sebagai berikut :

$$
\begin{array}{ll}
\mathrm{I}_{\text {rata }- \text { rata }} & =\frac{I R+I S+I T}{3} \\
\mathrm{I}_{\text {rata }- \text { rata }} & =\frac{133+186+134}{3}
\end{array}
$$

Analisa Efisiensi Transformator Penyulang Yang Dipengaruhi Oleh Ketidakseimbangan Beban Menggunakan Aplikasi Etap 12.6.0 
$\mathrm{I}_{\text {rata }- \text { rata }} \quad=151 \mathrm{~A}$

Untuk menghitung persentase beban maka digunakan rumus pada persamaan

(2.22) sebagai berikut :

$\%$ pembebanan $=\frac{\text { Irata }- \text { rata beban }}{\text { Ibeban penuh transformator }} \times 100 \%$

$\%$ pembebanan $=\frac{151 \mathrm{~A}}{231,2} \times 100 \%$

$\%$ pembebanan $=65,31 \%$

\section{d. Ketidakseimbangan Beban}

Oleh karena arus fasa dalam keadaan seimbang adalah arus rata-rata maka dalam kasus ini digunakan koefisien kesimbangan beban dimana $\mathrm{a}=\mathrm{b}=\mathrm{c}=1$. Sehingga untuk menghitung keseimbangan beban digunakan rumus $(2.24 ; 2.25 ; 2.26)$ sebagai berikut:

$\mathrm{a}=\frac{I R}{\text { Irata-rata }}=\frac{133}{151}=0,88 \mathrm{~A}$
$\mathrm{~b}=\frac{I S}{\text { Irata-rata }}=\frac{186}{151}=1,23 \mathrm{~A}$
$\mathrm{c}=\frac{I T}{\text { Irata-rata }}=\frac{134}{151}=0.88 \mathrm{~A}$

Untuk menghitung persentase ketidakseimbangan maka digunakan rumus (2.27) sebagai berikut :

$\%$ ketidakseimbangan $=\frac{\{|a-1|+|b-1|+|c-1|\}}{3} \times 100 \%$

$\%$ ketidakseimbangan $=\frac{\{|0,88-1|+|1,23-1|+|0,88-1|\}}{3} \times 100 \%$

$\%$ ketidakseimbangan $=15,66 \%$

\section{e. Rugi - Rugi Daya} berikut :

Dengan menggunakan rumus persamaan rugi-rugi daya dapat dihitung sebagai

$\sum=\mathrm{Pi}+\mathrm{Pcu}+\mathrm{Pn}$

$\sum=0,4+10,746873+2,277252=13,424398 \mathrm{KW}$

\section{f. Efisiensi Transformator}

Untuk menghitung efisiensi transformator dengan menggunakan rumus persamaan (2.15):

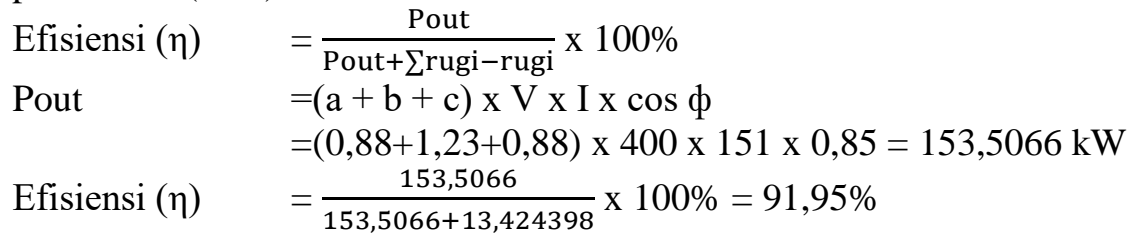

Dari perhitungan diatas menggunakan data lapangan, dapat diketahui besarnya nilai persentase pembebanan dan ketidakseimbangan beban pada gardu distribusi penyulang harimau pada table dibawah ini.

Tabel 4.1 Persentase Pembebanan, Ketidakseimbangan, Efisiensi Terhadap Standar SPLN 50 - 1997 Tahun 2021.

\begin{tabular}{|c|c|c|c|c|}
\hline $\begin{array}{c}\text { Nama } \\
\text { Gardu }\end{array}$ & $\begin{array}{c}\text { Pembebanan } \\
\text { Transformator } \\
(\%)\end{array}$ & $\begin{array}{c}\text { Ketidakseimbangan } \\
\text { Beban }(\%)\end{array}$ & $\begin{array}{c}\text { Efisiensi } \\
(\boldsymbol{\eta}) \%\end{array}$ & SPLN 50 - 1997 \\
\hline PA0255 & 22,02 & 1 & 93,4 & $\begin{array}{c}\text { Pembebanan dan } \\
\text { Efisiensi Tidak } \\
\text { Mencapai }\end{array}$ \\
\hline PA0257 & 65,31 & 15,66 & 91,95 & $\begin{array}{c}\text { Efisiensi Tidak } \\
\text { Mencapai }\end{array}$ \\
\hline
\end{tabular}

Analisa Efisiensi Transformator Penyulang Yang Dipengaruhi Oleh Ketidakseimbangan Beban Menggunakan Aplikasi Etap 12.6.0 


\begin{tabular}{|c|c|c|c|c|} 
PA0356 & 32,87 & 20 & 94,84 & $\begin{array}{c}\text { Efisiensi Tidak } \\
\text { Mencapai }\end{array}$ \\
\hline PA0407 & 41,08 & 24,6 & 93,63 & $\begin{array}{c}\text { Efisiensi Tidak } \\
\text { Mencapai }\end{array}$ \\
\hline PA0457 & 64,12 & 14,66 & 91,22 & $\begin{array}{c}\text { Efisiensi Tidak } \\
\text { Mencapai }\end{array}$ \\
\hline PA0513 & 50,27 & 32,33 & 97,59 & $\begin{array}{c}\text { Efisiensi Tidak } \\
\text { Mencapai }\end{array}$ \\
\hline PA0566 & 4 & 95 & 48,6 & $\begin{array}{c}\text { Pembebanan dan } \\
\text { Efisiensi Tidak } \\
\text { Mencapai }\end{array}$ \\
\hline PA0637 & 26,3 & 17,3 & 97,4 & $\begin{array}{c}\text { Efisiensi Tidak } \\
\text { Mencapai }\end{array}$ \\
\hline PA0663 & 7,1 & 42,3 & 96,1 & $\begin{array}{c}\text { Pembebanan dan } \\
\text { Efisiensi Tidak } \\
\text { Mencapai }\end{array}$ \\
\hline PA0726 & 52,11 & 31 & 94,92 & $\begin{array}{c}\text { Efisiensi Tidak } \\
\text { Mencapai }\end{array}$ \\
\hline
\end{tabular}

4.1.2. Hasil Perhitungan Menggunakan simulasi ETAP 12.6.0

Tabel 4.2 Persentase Pembebanan, Ketidakseimbangan, dan Efisiensi dari ETAP 12.6.0 Terhadap Standar SPLN 50 - 1997 Tahun 2021.

\begin{tabular}{|c|c|c|c|c|}
\hline $\begin{array}{c}\text { Nama } \\
\text { Gardu }\end{array}$ & $\begin{array}{c}\text { Pembebanan } \\
\text { Transformator } \\
(\boldsymbol{\%})\end{array}$ & $\begin{array}{c}\text { Ketidakseimbangan } \\
\text { Beban }(\boldsymbol{\%})\end{array}$ & $\begin{array}{c}\text { Efisiensi } \\
(\mathbf{\eta}) \mathbf{\%}\end{array}$ & SPLN 50 - 1997 \\
\hline PA0255 & 22,14 & 0,56 & 93,8 & $\begin{array}{c}\text { Pembebanan dan } \\
\text { Efisiensi Tidak } \\
\text { Mencapai }\end{array}$ \\
\hline PA0257 & 66,46 & 16 & 92,85 & $\begin{array}{c}\text { Efisiensi Tidak } \\
\text { Mencapai }\end{array}$ \\
\hline PA0356 & 33,1 & 20 & 94,49 & $\begin{array}{c}\text { Efisiensi Tidak } \\
\text { Mencapai }\end{array}$ \\
\hline PA0407 & 49,88 & 25,3 & 93,74 & $\begin{array}{c}\text { Efisiensi Tidak } \\
\text { Mencapai }\end{array}$ \\
\hline PA0457 & 65,05 & 14,66 & 91,51 & $\begin{array}{c}\text { Efisiensi Tidak } \\
\text { Mencapai }\end{array}$ \\
\hline PA0513 & 50,78 & 33,33 & 97,38 & $\begin{array}{c}\text { Efisiensi Tidak } \\
\text { Mencapai }\end{array}$ \\
\hline PA0566 & 4 & 95 & 49,05 & $\begin{array}{c}\text { Pembebanan dan } \\
\text { Efisiensi Tidak } \\
\text { Mencapai }\end{array}$ \\
\hline PA0637 & 26,3 & 17,3 & 97,4 & $\begin{array}{c}\text { Efisiensi Tidak } \\
\text { Mencapai }\end{array}$ \\
\hline PA0663 & 7,1 & 42,3 & 96,09 & $\begin{array}{c}\text { Pembebanan dan } \\
\text { Efisiensi Tidak } \\
\text { Mencapai }\end{array}$ \\
\hline PA0726 & 52,82 & 31,7 & 95,28 & $\begin{array}{c}\text { Efisiensi Tidak } \\
\text { Mencapai }\end{array}$ \\
\hline
\end{tabular}

\subsection{Analisa}

Analisa Efisiensi Transformator Penyulang Yang Dipengaruhi Oleh Ketidakseimbangan Beban Menggunakan Aplikasi Etap 12.6.0 
Untuk kondisi nilai efisiensi tertinggi pada perhitungan manual sendiri terdapat pada gardu distribusi PA 0513 dengan nilai persentase di angka 97,59\% dan untuk kondisi terendah sendiri terdapat pada gardu distribusi PA 0566 dengan nilai persentase di angka 48,6\%. Sedangkan pada simulasi ETAP didapatkan nilai persentase terbesar terhitung di gardu distribusi PA 0637 dengan nilai persentase efisiensi transformator $97,4 \%$ dan untuk nilai persentase yang rendah terhitung pada gardu distribusi PA 0566 dengan nilai persentase efisiensi transformator 49,05\%. Dari hasil perhitungan yang telah diperoleh menghasilkan bahwa kondisi transformator gardu distribusi penyulang harimau rata - rata semua gardu distribusi tidak ada yang mencapai standar yang mengacu ke pada SPLN 50 1997 tentang spesifikasi transformator bahkan ada yang nilai efisiensinya yang jauh untuk mencapai standar yaitu pada gardu distribusi PA 0566 mendapatkan nilai efisiensi 49,05\% untuk simulasi aplikasi ETAP dan 48,6\%.

\section{PENUTUP}

1. Terdapat ada 5 transformator di gardu distribusi pada penyulang harimau yang mengalami ketidakseimbangan buruk yaitu $>=25 \%$.

2. Ketidakseimbangan beban dapat mempengaruhi efisiensi karena akan ada arus yang mengalir pada penghantar netral saat kondisi pembebanan transformator mengalami ketidakseimbangan sehingga menyebabkan adanya rugi-rugi daya yang dapat menurunkan nilai efisiensi transformator yang digunakan.

\section{DAFTAR PUSTAKA}

[1] Prast, Eko. 2011. Generator Electrical Protection System. (http://projects87.blogspot.com/2009/02/generator-electrical-protection-relay.html, diakses 25 April 2021).

[2] Rakhman Alief. 2020. Relai-proteksi-pada-transformator. (https://rakhman.net/electricalid/relay-proteksi-pada-transformator/, diakses 25 April 2021).

[3] Hidayatullah, Nur. 2011. Fungsi Relay / Rele Proteksi. (http://blog.umy.ac.id/hidayat/2011/11/08/fungsi-relay-rele-proteksi/, diakses 25 April 2021).

[4] Saputra, Bayu. 2012. Syarat Relay Pengaman. (http://bayu93saputra.blogspot.com/2012/10/syarat-relay-pengaman.html, diakses 25 April 2021). 